Cite this: Phys. Chem. Chem. Phys. 2014, 16, 5399

Received 31st October 2013, Accepted 27th January 2014

DOI: $10.1039 / \mathrm{c} 3 \mathrm{cp} 54610 a$

www.rsc.org/pccp

\section{First-principles material modeling of solid-state electrolytes with the spinel structure}

\author{
Maarten J. Mees, ${ }^{\text {ab }}$ Geoffrey Pourtois, ${ }^{\text {bc }}$ Fabio Rosciano, ${ }^{d}$ Brecht Put, ${ }^{\text {ab }}$ \\ Philippe M. Vereecken ${ }^{\text {be }}$ and André Stesmans ${ }^{a}$
}

\begin{abstract}
Ionic diffusion through the novel $\left(\mathrm{Al}_{x} \mathrm{Mg}_{1-2 x} \mathrm{Li}_{x}\right) \mathrm{Al}_{2} \mathrm{O}_{4}$ spinel electrolyte is investigated using first-principles calculations, combined with the Kinetic Monte Carlo algorithm. We observe that the ionic diffusion increases with the lithium content $x$. Furthermore, the structural parameters, formation enthalpies and electronic structures of $\left(\mathrm{Al}_{x} \mathrm{Mg}_{1-2 x} \mathrm{Li}_{x}\right) \mathrm{Al}_{2} \mathrm{O}_{4}$ are calculated for various stoichiometries. The overall results indicate the $\left(\mathrm{Al}_{x} \mathrm{Mg}_{1-2 x} \mathrm{Li}_{x}\right) \mathrm{Al}_{2} \mathrm{O}_{4}$ stoichiometries $x=0.2 \ldots 0.3$ as most promising. The $\left(\mathrm{Al}_{x} \mathrm{Mg}_{1-2 x} \mathrm{Li}_{x}\right) \mathrm{Al}_{2} \mathrm{O}_{4}$ electrolyte is a potential candidate for the all-spinel solid-state battery stack, with the material epitaxially grown between well-known spinel electrodes, such as $\mathrm{Li}_{y} \mathrm{Mn}_{2} \mathrm{O}_{4}$ and $\mathrm{Li}_{4+3 y} \mathrm{Ti}_{5} \mathrm{O}_{12}(y=0 \ldots 1)$. Due to their identical crystal structure, a good electrolyte-electrode interface is expected.
\end{abstract}

\section{Introduction}

The increasing exploitation of renewable energy sources together with the inescapable need for novel energy storage devices are among the biggest challenges that our century is facing. In this respect, inexhaustible energy sources, such as solar and wind energy, have attracted attention to meet the ever increasing energy demand. These alternative energy sources are however not constant, requiring efficient energy storage solutions in order to be exploited. Among the wealth of specific device implementations found in literature and industry, the chemical energy storage ones (batteries) encountered much progress in recent years. However, numerous technical innovations are still needed to meet today's requirements in terms of energy and power density, safety, and durability. A promising device concept to meet these requirements is an all-solid-state Li-ion battery. ${ }^{1}$

The main advantages of all-solid-state batteries over conventional ones are improved safety and durability due to the absence of a liquid electrolyte, and the possibility of miniaturization. ${ }^{1-4}$ Although solid-state electrolytes often suffer from low ionic conductivity that limits the battery power capabilities, sufficiently thin electrolytes i.e. in the order of tens of nanometers - potentially have an overall

\footnotetext{
${ }^{a}$ Department of Physics, University of Leuven, Celestijnenlaan 200 D, B-3001 Leuven, Belgium. E-mail: meesm@imec.be; Tel: +32 16288174

${ }^{b}$ IMEC, Kapeldreef 75, B-3001 Leuven, Belgium

${ }^{c}$ Department of Chemistry, University of Antwerp, Universiteitsplein 1, B-2610 Wilrijk-Antwerp, Belgium

${ }^{d}$ Toyota Motor Europe, Advanced Technology 1, Hoge Wei 33, B-1930 Zaventem, Belgium

${ }^{e}$ Centre for Surface Chemistry and Catalysis, University of Leuven, Kasteelpark Arenberg 23, B-3001 Leuven, Belgium. E-mail: vereeck@imec.be; Tel: +3216288330
}

low resistance, as the resistance scales with the thickness of the electrolyte. A similar principle can be applied for electrodes in thin film batteries where the energy density increases by deposition of the active materials in 3D structures. ${ }^{5,6}$ Various literature reviews discuss the advantages and disadvantages of well-known inorganic ceramic and organic polymer solid-state electrolytes. $^{2-4}$ This work, however, focuses on the novel $\left(\mathrm{Al}_{x} \mathrm{Mg}_{1-2 x} \mathrm{Li}_{x}\right) \mathrm{Al}_{2} \mathrm{O}_{4}$ spinel electrolytes where $x$ varies between 0.0 and $0.5 .^{7}$

Rosciano et al. have recently proposed that $\left(\mathrm{Al}_{x} \mathrm{Mg}_{1-2 x} \mathrm{Li}_{x}\right)$ $\mathrm{Al}_{2} \mathrm{O}_{4}$ can be used as a solid electrolyte for an all-solid-state battery stack wherein the anode, electrolyte, and cathode each adopt the spinel cubic close packed symmetry. ${ }^{7,8}$ For example, an $\left(\mathrm{Al}_{x} \mathrm{Mg}_{1-2 x} \mathrm{Li}_{x}\right) \mathrm{Al}_{2} \mathrm{O}_{4}$ spinel electrolyte can be combined with well performing spinel structured electrodes, such as $\mathrm{Li}_{y} \mathrm{Mn}_{2} \mathrm{O}_{4}{ }^{9,10}$ and $\mathrm{Li}_{4+3 y} \mathrm{Ti}_{5} \mathrm{O}_{12}{ }^{11-13}(y=0 \ldots 1)$. Due to the similarity in crystal structures, low electrolyte-electrode interfacial resistances and continuous conduction paths throughout the device are expected, resulting in a potentially higher power output. Indeed, crystal structure matching can lead to a smooth interface with epitaxial growth, ${ }^{14}$ which results in a low resistance for ions to diffuse across the electrolyte-electrode interface. Depositing this all-spinel battery stack in a 3D template could increase both the energy and power density of the battery.,6

Besides their crystal structure, the electrolyte and electrodes should have a similar lattice constant to limit the appearance of interfacial stress. Indeed, close to the interface this stress could lead to an increasing defect concentration, or even cause the formation of new crystal phases. ${ }^{14}$ Consequently, a smooth electrolyte/electrode interface is lacking, resulting in an increased resistance for mobile ions to diffuse between the electrolyte and the electrode. Furthermore, the ionic conductivity of the electrolyte 
needs to be sufficiently high to provide a sustained power output. If a tens of nanometers thick electrolyte is considered, which is about $10^{2}-10^{4}$ times thinner than the electrolyte of a typical thin-film battery, ${ }^{15}$ then an ionic conductivity in the order of $10^{-6}-10^{-8} \mathrm{~S} \mathrm{~cm}^{-1}$ would compete with other commercially available electrolytes. ${ }^{15}$ Indeed, as the best conductors have ionic conductivities in the order of $10^{-2}-10^{-4} \mathrm{~S} \mathrm{~cm}^{-1}$, the shorter diffusion path of the more resistive electrolyte results in a similar resistance as the resistance scales with length. Finally, the $\left(\mathrm{Al}_{x} \mathrm{Mg}_{1-2 x} \mathrm{Li}_{x}\right) \mathrm{Al}_{2} \mathrm{O}_{4}$ electrolytes should be electrochemically stable and electronically insulating, as validated experimentally. ${ }^{7}$

We report here first-principles density functional theory (DFT) simulations on the $\left(\mathrm{Al}_{x} \mathrm{Mg}_{1-2 x} \mathrm{Li}_{x}\right) \mathrm{Al}_{2} \mathrm{O}_{4}$ spinel electrolytes to investigate their lattice constants and ionic conductivities. The lattice constants are compared to those of the $\mathrm{LiMn}_{2} \mathrm{O}_{4}$ and $\mathrm{Li}_{4} \mathrm{Ti}_{5} \mathrm{O}_{12}$ spinel electrodes, whereas the ionic conductivities are examined against the standard discussed above, i.e. $10^{-6}$ $10^{-8} \mathrm{~S} \mathrm{~cm}^{-1}$. Furthermore, the formation enthalpy of lithiation of the spinel

$$
(1-2 x) \mathrm{MgAl}_{2} \mathrm{O}_{4}+x \mathrm{LiAl}_{5} \mathrm{O}_{8} \rightarrow\left(\mathrm{Al}_{x} \mathrm{Mg}_{1-2 x} \mathrm{Li}_{x}\right) \mathrm{Al}_{2} \mathrm{O}_{4}
$$

is calculated. These thermodynamical calculations are used to evaluate the boundary of solubility and of phase separation during the synthesis of the $\left(\mathrm{Al}_{x} \mathrm{Mg}_{1-2 x} \mathrm{Li}_{x}\right) \mathrm{Al}_{2} \mathrm{O}_{4}$ electrolytes. Finally, the electronically insulating character of $\left(\mathrm{Al}_{x} \mathrm{Mg}_{1-2 x} \mathrm{Li}_{x}\right)^{-}$ $\mathrm{Al}_{2} \mathrm{O}_{4}$ is confirmed by calculating the electronic structures of the stoichiometries $x=0.0,0.25$, and 0.5 . This work, together with the solubility, lattice constants, and $\mathrm{Li}^{+}$self-diffusion measurements of Rosciano et al., ${ }^{7}$ describes most of the key physical parameters that define the applicability of the $\left(\mathrm{Al}_{x} \mathrm{Mg}_{1-2 x} \mathrm{Li}_{x}\right)^{-}$ $\mathrm{Al}_{2} \mathrm{O}_{4}$ spinel materials as solid-state electrolytes for the all-spinel battery stack.

The paper is structured as follows: we first focus on the methodology aspect, in which the details of the crystal structure and modeling assumptions are reviewed. Next, the lattice constants, formation enthalpies and electronic structures are discussed. Finally, the ionic conductivity mechanisms are investigated.

\section{Methodology}

The solid-state electrolyte $\left(\mathrm{Al}_{x} \mathrm{Mg}_{1-2 x} \mathrm{Li}_{x}\right) \mathrm{Al}_{2} \mathrm{O}_{4}$ derives from the $\mathrm{MgAl}_{2} \mathrm{O}_{4}$ spinel, as the electrolyte is formed from the latter by the substitution of every two $\mathrm{Mg}^{2+}$ cations by one $\mathrm{Li}^{+}$and one $\mathrm{Al}^{3+}$ cation. ${ }^{7}$ The $\mathrm{MgAl}_{2} \mathrm{O}_{4}$ spinel has a cubic unit cell containing 56 atoms: 32 anions and 24 cations. The 32 anions are $\mathrm{O}^{2-}$ ions occupying the 32e Wyckoff positions, whereas the 24 cation sites are divided over eight tetrahedrally coordinated $\mathrm{Mg}^{2+}$ ions and 16 octahedrally coordinated $\mathrm{Al}^{3+}$ ions that are respectively the $8 \mathrm{a}$ and 16d Wyckoff positions. These coordinates and positions are presented in Table 1 and Fig. 1.

Because the $\mathrm{MgAl}_{2} \mathrm{O}_{4}$ unit cell contains eight $\mathrm{Mg}^{2+}$ crystal structure sites, numerous configurations for $\left(\mathrm{Al}_{x} \mathrm{Mg}_{1-2 x} \mathrm{Li}_{x}\right)^{-}$ $\mathrm{Al}_{2} \mathrm{O}_{4}$ can be constructed by reorganizing the $\mathrm{Mg}^{2+}, \mathrm{Li}^{+}$and $\mathrm{Al}^{3+}$ ions. For example, when the lithium concentration $x$ in $\left(\mathrm{Al}_{x} \mathrm{Mg}_{1-2 x} \mathrm{Li}_{x}\right) \mathrm{Al}_{2} \mathrm{O}_{4}$ equals 0.25 , the unit cell contains two $\mathrm{Li}^{+}$
Table 1 Structural data for the $\mathrm{MgAl}_{2} \mathrm{O}_{4}$ spinel. The space group is $\mathrm{Fd} \overline{3} \mathrm{~m}$ with lattice constant $a=8.09 \AA^{16}$

\begin{tabular}{lrlll}
\hline Atom & Site & $x / a$ & $y / a$ & $z / a$ \\
\hline $\mathrm{Mg}^{2+}$ & $8 \mathrm{a}$ & 0.000 & 0.000 & 0.000 \\
$\mathrm{Al}^{3+}$ & $16 \mathrm{~d}$ & 0.625 & 0.625 & 0.625 \\
$\mathrm{O}^{2-}$ & $32 \mathrm{e}$ & 0.389 & 0.389 & 0.389
\end{tabular}

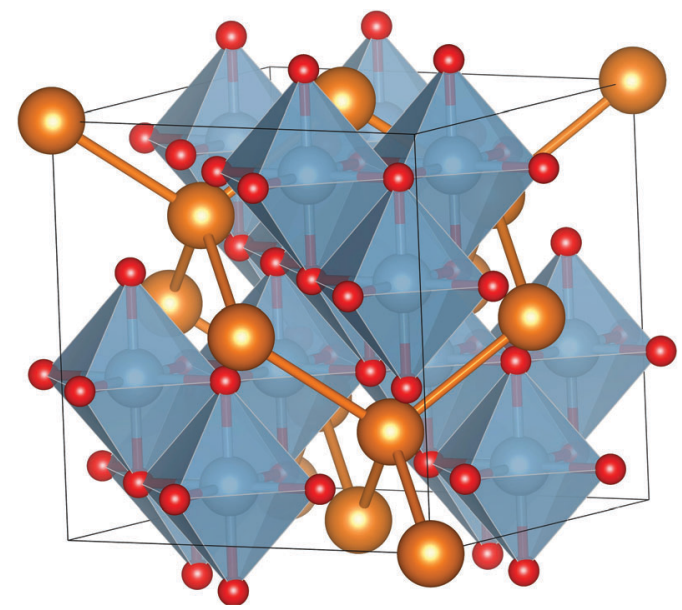

Fig. 1 Crystal structure of $\mathrm{MgAl}_{2} \mathrm{O}_{4}$. The $\mathrm{Mg}^{2+}$ cations are represented by the tetrahedrally coordinated gold atoms, whereas the $\mathrm{Al}^{3+}$ cations are the octahedral coordinated blue atoms that are surrounded by six oxygen anions (red atoms).

ions, two $\mathrm{Al}^{3+}$ ions, and four $\mathrm{Mg}^{2+}$ ions, resulting in over 420 different structural combinations. Given this large number of combinations, a full first-principles study on these materials would be very time consuming. However, the symmetry group of the spinel materials, i.e. $F d \overline{3} m$ that contains 192 symmetry elements, makes a large part of these 420 structures redundant, leading to seven non-equivalent unit cells. This reduction by symmetry is applied to all the calculations performed, leading to a significant decrease of the computational effort while maintaining a complete material description.

First-principles calculations are performed using the Quantum Espresso (QE) package that applies a plane-wave basis set and periodic boundary conditions. ${ }^{17}$ The Kohn-Sham equations of the density functional theory (DFT) have been solved using the PBE generalized gradient approximation ${ }^{18}$ and the ultra-soft pseudopotentials (USPP). ${ }^{19}$ The plane-wave energy cut-off and the number of $k$-points in the Monkhorst-Pack grid are respectively set to a 36 Ry cut-off energy and a $2 \times 2 \times 2 k$-point grid. For the Density of States (DOS) calculations, we applied an $8 \times 8 \times 8 k$-point grid.

The diffusion coefficient of a $\mathrm{Li}^{1-}$ vacancy in $\left(\mathrm{Al}_{x} \mathrm{Mg}_{1-2 x} \mathrm{Li}_{x}\right)$ $\mathrm{Al}_{2} \mathrm{O}_{4}$ is found using a Kinetic Monte Carlo (KMC) algorithm. ${ }^{20-22}$ First, a sufficiently large supercell is created containing $5 \times 5 \times 5$ randomly sampled spinel unit cells of the chosen stoichiometry $x$, in which one $\mathrm{Li}^{1-}$ vacancy is introduced. Next, the algorithm establishes the $\mathrm{Li}^{1-}$ vacancy neighbors that can exchange place with the vacancy. In this step, some physical constraints have been introduced to limit the number of possible reaction paths to the 
physically relevant ones. This essential intuitive input, intrinsic to most KMC algorithms, ${ }^{23}$ is further discussed below. Once the program found the relevant $\mathrm{Li}^{1-}$ vacancy adjacent cations, it continues with the search of the least-energy reaction paths of the vacancy-neighbor exchanges. These paths are evaluated by applying the QE Nudged Elastic Band (NEB) algorithm using the climbing image method. ${ }^{24}$ As stated above, our approach exploits the material symmetry, hereby significantly reducing the number of NEB calculations. Once these calculations are complete, the KMC-algorithm chooses a statistically correct vacancy-neighbor exchange event based on the calculated reaction paths. These steps are repeated until vacancy migration paths can be obtained with a sufficiently long time span to extract a vacancy diffusion coefficient.

The applied KMC algorithm initially evolves slowly because most vacancy-neighbor exchanges lead to an unknown vacancy environment, implying the computation of time-consuming NEB paths. Nevertheless, once the number of KMC iterations increase, the impact of most chemical environments is gradually known, thereby reducing the number of NEB calculations to be performed. Ultimately, all the possible variations in the environment are known, resulting in negligible simulation times to find extended vacancy paths. Notably, in this limit the temperature dependence on the vacancy diffusion is readily found within the KMC formalism. Our results indicate a Arrhenius-like behavior of the diffusion coefficient

$$
D=D_{0} \exp \left(-\frac{E_{\mathrm{a}}}{k_{\mathrm{B}} T}\right),
$$

with $D_{0}$ the pre-exponential diffusion constant, $E_{\mathrm{a}}$ the activation energy of diffusion, $k_{\mathrm{B}}$ Boltzman's constant, and $T$ the absolute temperature.

Our algorithm collected 235 unique vacancy reaction paths for various $\left(\mathrm{Al}_{x} \mathrm{Mg}_{1-2 \mathrm{x}} \mathrm{Li}_{x}\right) \mathrm{Al}_{2} \mathrm{O}_{4}$ stoichiometries, which represent nearly all the possible reaction mechanisms that could occur in these materials. These vacancy-cation exchange paths are divided over the $\left(\mathrm{Al}_{x} \mathrm{Mg}_{1-2 x} \mathrm{Li}_{x}\right) \mathrm{Al}_{2} \mathrm{O}_{4}$ stoichiometries, with a division for the lithium concentration $x$ as: 0.125 (77 paths), 0.25 (139 paths), and 0.5 (19 paths). The Arrhenius plots for these different stoichiometries are obtained by sampling the average diffusion coefficient of $10 \mathrm{KMC}$ simulations for a set of temperatures ranging between $300 \mathrm{~K}$ and $900 \mathrm{~K}$. The KMC paths contain $104 \mathrm{KMC}$ steps resulting in different time spans for different temperatures; going from seconds at $300 \mathrm{~K}$, to tens of picoseconds at $900 \mathrm{~K}$. The temperature interval was set to $100 \mathrm{~K}$. For each $\mathrm{KMC}$ path, the corresponding diffusion coefficient is found by the Einstein relation

$$
D=\lim _{\Delta t \rightarrow \infty} \frac{\sqrt{\left\langle\left(\mathbf{r}\left(t_{0}+\Delta t\right)-\mathbf{r}\left(t_{0}\right)\right)^{2}\right\rangle}}{6 \Delta t}
$$

whereby the mean square displacement $\left\langle\left(\mathbf{r}\left(t_{0}+\Delta t\right)-\mathbf{r}\left(t_{0}\right)\right)^{2}\right\rangle$ is found by using different time origins $t_{0}$.

\section{Results and discussion}

Fig. 2 shows the evolution of the lattice parameters computed for different $\left(\mathrm{Al}_{x} \mathrm{Mg}_{1-2 x} \mathrm{Li}_{x}\right) \mathrm{Al}_{2} \mathrm{O}_{4}$ stoichiometries with $x$ equal to

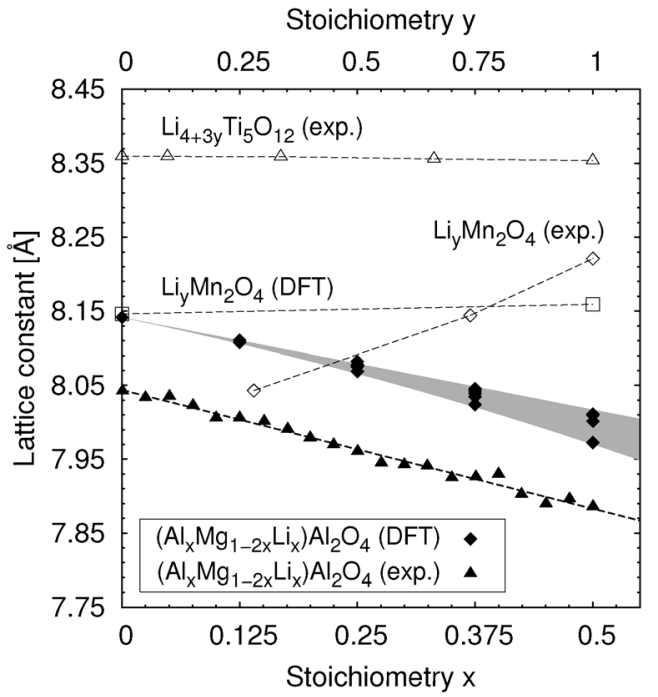

Fig. 2 The calculated lattice constants of $\left(\mathrm{Al}_{x} \mathrm{Mg}_{1-2 x} \mathrm{Li}_{x}\right) \mathrm{Al}_{2} \mathrm{O}_{4}$ for different stoichiometries $(x=0.0,0.125,0.25,0.375,0.5)$, together with those obtained experimentally. ${ }^{7}$ The experimental lattice constants of $\mathrm{Li}_{y} \mathrm{Mn}_{2} \mathrm{O}_{4}$ and $\mathrm{Li}_{4+3 y} \mathrm{Ti}_{5} \mathrm{O}_{12}$ are respectively represented by the open diamonds and triangles. $^{25,26}$ The open squares represent the lattice constants of $\mathrm{Li}_{y} \mathrm{Mn}_{2} \mathrm{O}_{4}$ obtained using first-principles calculations. ${ }^{27}$

$0.0,0.125,0.25,0.375$, and 0.5 . A slowly linear descending trend is observed for increasing lithium concentration, from $8.15 \AA$ to $8.00 \AA$ A This negative slope is in accordance with experimental reports. ${ }^{7}$ However, the simulated values are about $1 \%$ larger than those obtained experimentally. This mismatch is attributed to a typical overestimation by the PBE exchange-correlation functional. ${ }^{28}$ Furthermore, Fig. 2 shows that the distribution of lattice parameters of the $\left(\mathrm{Al}_{x} \mathrm{Mg}_{1-2 x} \mathrm{Li}_{x}\right) \mathrm{Al}_{2} \mathrm{O}_{4}$ electrolyte yield values slightly smaller than those reported for the $\mathrm{Li}_{y} \mathrm{Mn}_{2} \mathrm{O}_{4}$ electrode $(8.10 \pm 0.1 \AA) .{ }^{25}$ On the other hand, the reported values of the $\mathrm{Li}_{4+3 y} \mathrm{Ti}_{5} \mathrm{O}_{12}$ electrode (8.36 $⿱$ $)$ reveal a large mismatch of more than $3 \%$ with the $\left(\mathrm{Al}_{x} \mathrm{Mg}_{1-2 x} \mathrm{Li}_{x}\right) \mathrm{Al}_{2} \mathrm{O}_{4}$ electrolyte cell parameters. $^{26,27}$

The calculated lattice constants of $\left(\mathrm{Al}_{x} \mathrm{Mg}_{1-2 x} \mathrm{Li}_{x}\right) \mathrm{Al}_{2} \mathrm{O}_{4}$ for the different lithium concentrations are in good agreement with experimental data; ${ }^{7}$ however, their values diverge from the $\mathrm{Li}_{4+3 y} \mathrm{Ti}_{5} \mathrm{O}_{12}$ electrode $(8.35 \pm 0.05 \AA)^{26,29}$ The $\left(\mathrm{Al}_{x} \mathrm{Mg}_{1-2 x} \mathrm{Li}_{x}\right)$ $\mathrm{Al}_{2} \mathrm{O}_{4}$ cell parameters are close to those of $\mathrm{Li}_{y} \mathrm{Mn}_{2} \mathrm{O}_{4}$, but show a larger cell mismatch of more than $3 \%$ with the $\mathrm{Li}_{4+3 y} \mathrm{Ti}_{5} \mathrm{O}_{12}$ electrode, indicating that either a higher defect density or phase separation at this electrolyte-electrode interface could occur. On the other hand, the very similar lattice parameters of $\mathrm{Li}_{y} \mathrm{Mn}_{2} \mathrm{O}_{4}$ indicate that an epitaxial interface could be made.

The formation enthalpies of $\left(\mathrm{Al}_{x} \mathrm{Mg}_{1-2 x} \mathrm{Li}_{x}\right) \mathrm{Al}_{2} \mathrm{O}_{4}$ are computed from those of the isolated $\mathrm{MgAl}_{2} \mathrm{O}_{4}$ and $\mathrm{LiAl}_{5} \mathrm{O}_{8}$ components according to the reaction

$$
(1-2 x) \mathrm{MgAl}_{2} \mathrm{O}_{4}+x \mathrm{LiAl}_{5} \mathrm{O}_{8} \rightarrow\left(\mathrm{Al}_{x} \mathrm{Mg}_{1-2 x} \mathrm{Li}_{x}\right) \mathrm{Al}_{2} \mathrm{O}_{4}
$$

for different stoichiometries $(x=0.125,0.25,0.375,0.5)$, as presented in Fig. 3. These formation energies are endothermic and increase with the Li concentration, reaching values close to ten times the room-temperature thermal energy at $x$ equal to 0.5 . 


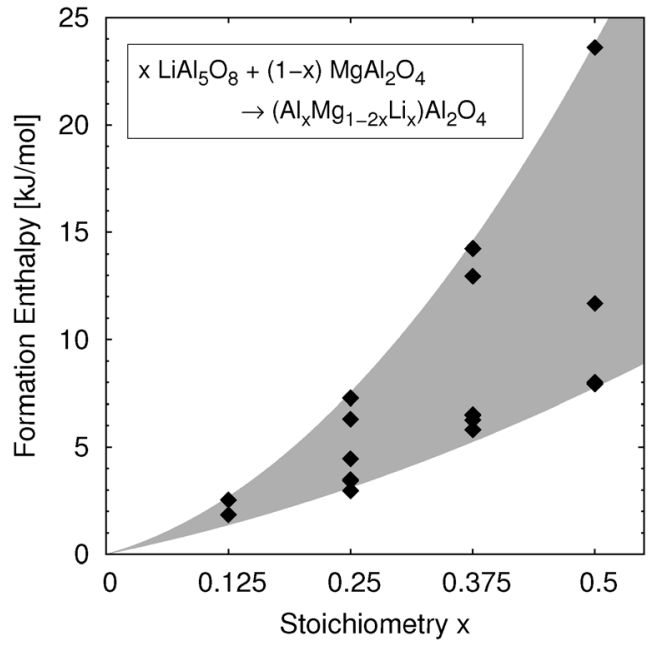

Fig. 3 The formation enthalpy of the reaction: $x \mathrm{LiAl}_{5} \mathrm{O}_{8}+(1-x) \mathrm{MgAl}_{2} \mathrm{O}_{4} \rightarrow$ $\left(\mathrm{Al}_{x} \mathrm{Mg}_{1-2 x} \mathrm{Li}_{x}\right) \mathrm{Al}_{2} \mathrm{O}_{4}$ for $x$ equal to $0.0,0.125,0.375$, and 0.5 .

The introduction of lithium in the unit cell leads to an increasing spread for both lattice constants and formation enthalpies.

The endothermic formation enthalpy of the above reaction illustrates the possible impact of the thermal conditions to synthesize crystalline $\left(\mathrm{Al}_{x} \mathrm{Mg}_{1-2 x} \mathrm{Li}_{x}\right) \mathrm{Al}_{2} \mathrm{O}_{4}$. Indeed, inadequate thermal treatment of the as-deposited materials could lead to a phase separation of $\mathrm{MgAl}_{2} \mathrm{O}_{4}$ and $\mathrm{LiAl}_{5} \mathrm{O}_{8}$. This segregation process is more likely to occur at higher lithium concentrations due to the more pronounced endothermicity of the reaction. As a matter of fact, at these higher concentrations, XRD experiments on $900{ }^{\circ} \mathrm{C}$ annealed $\left(\mathrm{Al}_{x} \mathrm{Mg}_{1-2 x} \mathrm{Li}_{x}\right) \mathrm{Al}_{2} \mathrm{O}_{4}$ powders reveal deterioration of the X-ray signal with respect to the signature expected for the $F d \overline{3} m$ spinel. ${ }^{30}$ This phenomenon could be explained, in accordance with our enthalpies result, by a segregation of the $\mathrm{Li}^{+}$ions that would result in the formation of lower energy $\mathrm{LiAl}_{5} \mathrm{O}_{8}$ grains with a $P 4_{3} 32$ crystal symmetry.

In Fig. 2 and 3, the number of non-equivalent configurations per stoichiometry is two $(x=0.125)$, seven $(x=0.25,0.375)$, and four $(x=0.5)$. A few of these data points are not visible, because of overlap. This occurs for configurations that are similar, resulting in nearly equal formation enthalpies or lattice constants.

In the preceding paragraphs, the $\mathrm{Li}^{+}$cations are positioned on the (8a) Wyckoff positions. Fig. 4 illustrates that, for different stoichiometries $(x=0.125,0.25,0.375)$, these are indeed energetically the most favourable positions for both $\mathrm{Li}^{+}$and $\mathrm{Mg}^{2+}$. An average energy penalty of more than $0.5 \mathrm{eV}$ is observed when a $\mathrm{Li}^{+}$or $\mathrm{Mg}^{2+}$ (8a) cation exchanges position with an $\mathrm{Al}^{3+}$ (16d) cation. Such high energy penalties result in negligible concentrations of octahedral $\mathrm{Li}^{+}$or $\mathrm{Mg}^{2+}$ cations when the $\left(\mathrm{Al}_{x} \mathrm{Mg}_{1-2 x} \mathrm{Li}_{x}\right) \mathrm{Al}_{2} \mathrm{O}_{4}$ is annealed up to $900{ }^{\circ} \mathrm{C}$. Interestingly, however, ${ }^{7} \mathrm{Li}$ MAS NMR experiments on $\left(\mathrm{Al}_{x} \mathrm{Mg}_{1-2 x} \mathrm{Li}_{x}\right) \mathrm{Al}_{2} \mathrm{O}_{4}$ report strong signatures of (16d) positioned $\mathrm{Li}^{+}$cations for stoichiometries $x>0.25$. $^{7}$ Because in the $P 4_{3} 32$ crystal symmetry of $\mathrm{LiAl}_{5} \mathrm{O}_{8}$ the $\mathrm{Li}^{+}$cations are located in the (16d) Wyckoff positions, this indeed suggests that at higher lithium concentrations, phase separation to $\mathrm{LiAl}_{5} \mathrm{O}_{8}$ and $\mathrm{MgAl}_{2} \mathrm{O}_{4}$ occurs.

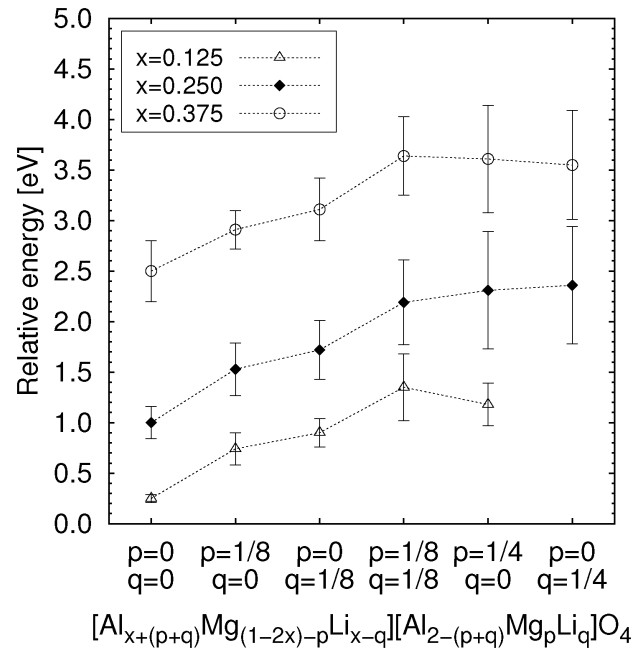

Fig. 4 Relative energies for different $\left(\mathrm{Al}_{x} \mathrm{Mg}_{1-2 x} \mathrm{Li}_{x}\right) \mathrm{Al}_{2} \mathrm{O}_{4}$ stoichiometries $(x=0.125,0.25,0.375)$ for several concentrations of $\mathrm{Li}^{+}$or $\mathrm{Mg}^{2+}(16 \mathrm{~d})$ cations. Herein $q$ is the percentage of $\mathrm{Li}^{+}$that exchanges position with an $\mathrm{Al}^{3+}(16 \mathrm{~d})$ cation, whereas $p$ represents the exchange percentage of $\mathrm{Mg}^{2+}$.

The increasing spread in the formation enthalpy at higher lithium concentrations observed in Fig. 3 leads to preferential and non-preferential combinations of the $\mathrm{Li}^{+}$and $\mathrm{Al}^{3+}$ ions in their $\mathrm{Mg}^{2+}$ crystal structure sites. We observe that for the nonpreferential combinations, represented by the higher formation enthalpies, the $\mathrm{Li}^{+}$ions have mainly $\mathrm{Li}^{+}$or $\mathrm{Al}^{3+}$ ion neighbors. Conversely, the lower formation enthalpies are combinations in which $\mathrm{Li}^{+}$ions have a nearly equal amount of $\mathrm{Li}^{+}$and $\mathrm{Al}^{3+}$ neighbors. The overall results indicate an energetic stabilization of the structure when the average oxidation state of a tetrahedrally coordinated cation neighborhood is close to the + II oxidation state of the magnesium cations. This is further illustrated in Fig. 5.

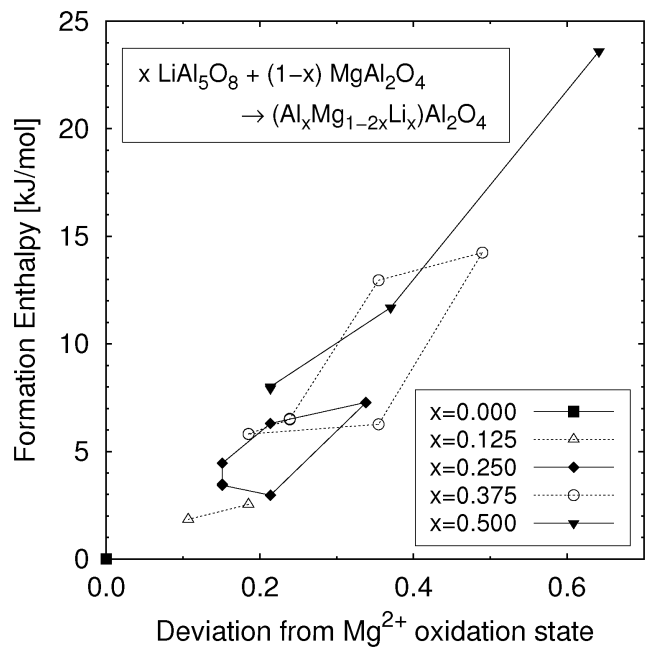

Fig. 5 Evaluation of the formation enthalpy as a function of the standard deviation of its local charges: $\sigma=\sqrt{\sum_{i=1}^{8}\left(\mu_{i}-2\right)^{2} / 7}$. Herein $\left(\mu_{i}\right)$ is an average oxidation state of a (8a) cation neighborhood, as illustrated in Fig. 6. 

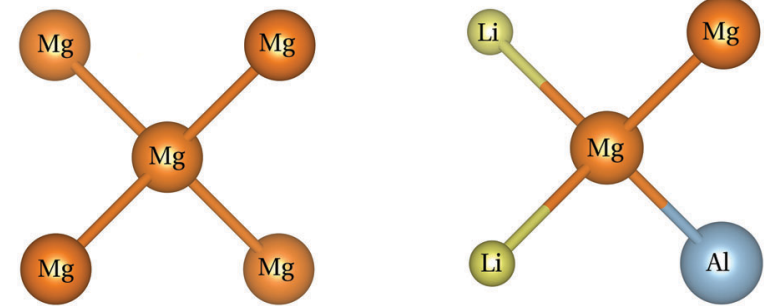

Fig. 6 The average oxidation state of a (8a) neighbourhood is the average value of the oxidation states of a (8a) cation and its four (8a) cation neighbours. For left this average is given by $\mu_{i}=2$, whereas for right it is given by $\mu_{i}=1.8$.

The formation energy of $\left(\mathrm{Al}_{x} \mathrm{Mg}_{1-2 x} \mathrm{Li}_{x}\right) \mathrm{Al}_{2} \mathrm{O}_{4}$ increases when the average oxidation states of the tetrahedrally coordinated (8a) cation neighborhoods increasingly deviate from the + II oxidation state of a magnesium cation, as presented in Fig. 5 for different stoichiometries $(x=0.125,0.25,0.375,0.5)$. This deviation is defined as

$$
\sigma=\sqrt{\frac{\sum_{i=1}^{8}\left(\mu_{i}-2\right)^{2}}{7}}
$$

in which $\left(\mu_{i}\right)_{i=1 \ldots 8}$ are the average oxidation states of the eight (8a) cation neighborhoods in a $\left(\mathrm{Al}_{x} \mathrm{Mg}_{1-2 x} \mathrm{Li}_{x}\right) \mathrm{Al}_{2} \mathrm{O}_{4}$ unit cell. This average oxidation state of a (8a) cation neighborhood is computed to be the average value of the oxidation states of a (8a) cation-i.e. a cation occupying a $\mathrm{Mg}^{2+}$ crystal position-and its four (8a) neighbors, as illustrated in Fig. 6 . These results indicate that local clustering of $\mathrm{Li}^{+}$or $\mathrm{Al}^{3+}$ ions in the unit cell evokes an electrostatic off-balanced configuration compared to the $\mathrm{Mg}^{2+}$ equilibrium state. As the likeliness of clustering increases with the $\mathrm{Li}^{+}$concentration, it leads to a broadening of the spread in the formation enthalpy as observed in Fig. 3.

The Density of States (DOS) of $\left(\mathrm{Al}_{x} \mathrm{Mg}_{1-2 x} \mathrm{Li}_{x}\right) \mathrm{Al}_{2} \mathrm{O}_{4}$ does not change significantly between the stoichiometries $x=0.0,0.25$,

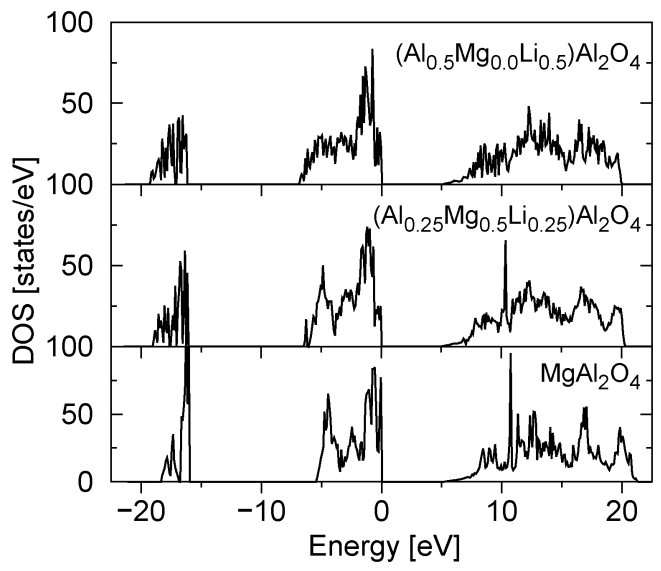

Fig. 7 The Density of State (DOS) for the $\left(\mathrm{Al}_{x} \mathrm{Mg}_{1-2 x} \mathrm{Li}_{x}\right) \mathrm{Al}_{2} \mathrm{O}_{4}$ stoichiometries $x=0.0,0.25$, and 0.5 . The top of the valence band is set at $E=0 \mathrm{eV}$. The DOS is calculated with the PBE exchange correlation functional for the most stable configurations in Fig. 3. and 0.5 , as shown in Fig. 7. The band-gap value is slightly more than $5 \mathrm{eV}$, confirming the electronically insulating character of the electrolyte. ${ }^{7}$ From the projected DOS (not shown here) we observe that the small changes in the conduction and valence bands are due to the substitutions in the (8a) Wyckoff positions, i.e. the replacement of the $\mathrm{Mg}^{2+}$ cations by the $\mathrm{Li}^{+}$and $\mathrm{Al}^{3+}$ cations. The band-gap, however, remains unaffected. This suggests that the band-gap value is mainly determined by the interaction between the (16c) $\mathrm{Al}^{3+}$ and (32e) $\mathrm{O}^{2-}$ ions.

Ionic conductivity in the $\left(\mathrm{Al}_{x} \mathrm{Mg}_{1-2 x} \mathrm{Li}_{x}\right) \mathrm{Al}_{2} \mathrm{O}_{4}$ electrolytes is studied by examining a $\mathrm{Li}^{1-}$ vacancy motion. Indeed, a charged battery discharges due to the difference in electrochemical potentials of the battery electrodes in contact with the electrolyte, causing an electron flow in the battery outer circuit. As a result, electron excess is created in the cathode that is reduced by indiffusion of $\mathrm{Li}^{+}$from the electrolyte. This migration of $\mathrm{Li}^{+}$from the $\left(\mathrm{Al}_{x} \mathrm{Mg}_{1-2 x} \mathrm{Li}_{x}\right) \mathrm{Al}_{2} \mathrm{O}_{4}$ electrolyte towards the cathode creates $\mathrm{Li}^{1-}$ vacancies near the cathode-electrolyte interface that start diffusing through the electrolyte towards the anode.

Certain neighbors of the vacancy in the $\left(\mathrm{Al}_{x} \mathrm{Mg}_{1-2 x} \mathrm{Li}_{x}\right) \mathrm{Al}_{2} \mathrm{O}_{4}$ electrolyte are more likely to exchange places than others. For example, an $\mathrm{O}^{2-}$ ion will not jump into a vacancy located on a $\mathrm{Mg}^{2+}$ site due to the electrostatic repulsion between the $\mathrm{O}^{2-}$ ion and the $\mathrm{Li}^{1-}$ vacancy, and because the $\mathrm{Mg}^{2+}$ site is chemically unfavorable for the $\mathrm{O}^{2-}$ anion. However, we calculated that an $\mathrm{Al}^{3+}$ ion in the octahedral coordinated site (16d) can exchange places with a vacancy in the tetrahedral site, but only by overcoming a high $\pm 3 \mathrm{eV}$ energy barrier (not shown here), which is consistent with the results reported on $\mathrm{MgAl}_{2} \mathrm{O}_{4}$ by Murphy et al. ${ }^{31}$ Interestingly, this study suggests that diffusion mainly takes place in the tetrahedral sites, corresponding to what we observe. Therefore, we only consider that the $\mathrm{Li}^{1-}$ vacancy exchanges with adjacent cations in tetrahedral sites.

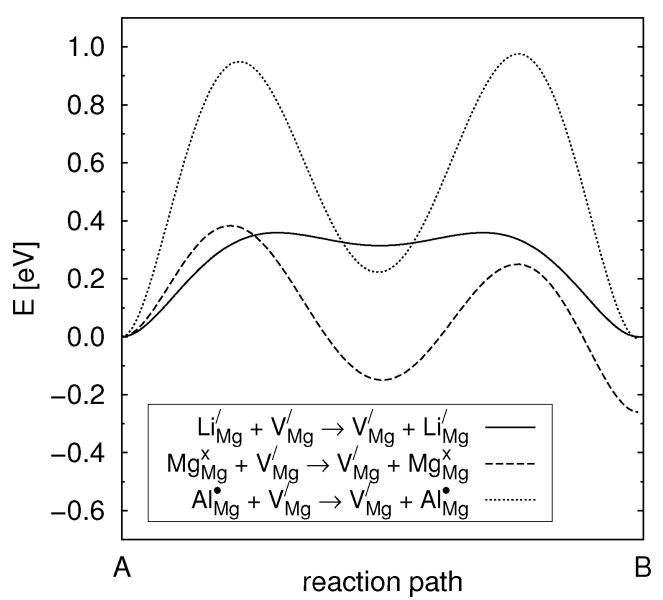

Fig. 8 Illustration of typical minimal energy paths found for a vacancy exchanging positions with an adjacent $\mathrm{Li}^{+}, \mathrm{Mg}^{2+}$, or $\mathrm{Al}^{3+}$ cation. The intermediate energy valley corresponds to a $16 \mathrm{c}$ Wyckoff position, whereas the initial and final valleys correspond to 8 a Wyckoff positions. The Kröger-Vink notation in the legend provides further details on the energy paths. The superscripts $\times, \cdot$ and ' respectively denote a neutral, a single positive, and a single negative charge. Finally, the subscript represents the crystal position of the element. 
A stable interstitial state is observed when a $\mathrm{Li}^{1-}$ vacancy exchanges its coordinates with an $\mathrm{Al}^{3+}$ or $\mathrm{Mg}^{2+}$ (8a) neighbor, as shown in Fig. 8. These stable states, that correspond to the $16 \mathrm{c}$ Wyckoff positions, are however not present when $\mathrm{Li}^{+}$moves into the vacancy. We define the effective rate, used for the $\mathrm{Al}^{3+}$ and $\mathrm{Mg}^{2+}$ exchanges, as

$$
k_{\mathrm{eff}}=\frac{k_{\mathrm{f}} k_{\mathrm{f}^{\prime}}}{\left(k_{\mathrm{f}}+k_{\mathrm{f}^{\prime}}\right)+k_{\mathrm{b}}}
$$

with $k_{\mathrm{f}}$ and $k_{\mathrm{f}^{\prime}}$ the rates of the forward jumps across respectively the first and second barrier, and $k_{\mathrm{b}}$ the rate of a backwards jump from the interstitial position to the initial position. The effective rate equals the rate of a "real" jump event, when an adjacent (8a) cation switches place with the vacancy. We observe that the effective energy barrier is mainly determined by the largest one that the exchanging ion encounters in its path towards the vacancy. The effective pre-exponential frequency factor is reduced by a factor of two to three because of the stable (16c) interstitial position. In the KMC formalism this pre-exponential frequency factor was set to $10 \mathrm{THz},{ }^{32}$ resulting in an effective pre-exponential frequency factor of about $4 \mathrm{THz}$.

Fig. 9 shows the effective energy barriers computed for a vacancy to exchange position with an adjacent $\mathrm{Mg}^{2+}, \mathrm{Li}^{+}$, or $\mathrm{Al}^{3+}$ cation. These activation energies do not change significantly for the different $\left(\mathrm{Al}_{x} \mathrm{Mg}_{1-2 x} \mathrm{Li}_{x}\right) \mathrm{Al}_{2} \mathrm{O}_{4}$ stoichiometries, however, the average value and the spread differ for the nature of the exchanged cations. $\mathrm{A} \mathrm{Li}^{1+}$ cation exchanges position with a vacancy by crossing a fairly low energy barrier of about $0.35 \mathrm{eV}$, that is similar to the experimental values. ${ }^{7}$ The energy barrier of $\mathrm{Li}^{1+}$ is close to $75 \%$ of the value computed for $\mathrm{a} \mathrm{Mg}^{2+}$ ion exchange. On the other hand, the $\mathrm{Al}^{3+}$ ions have to overcome a higher energy barrier of slightly more than $1 \mathrm{eV}$, resulting in negligible diffusion compared to $\mathrm{Li}^{+}$and $\mathrm{Mg}^{2+}$ at room temperature. In general, stoichiometries with a high $\mathrm{Li}^{+}$concentration are assumed to have better ionic conductivity, as in these materials the vacancies are

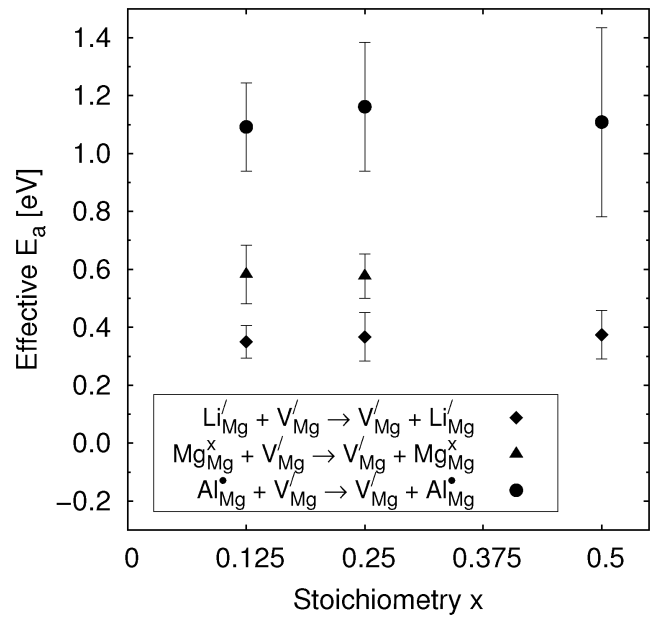

Fig. 9 Effective energy barrier computed for a set of possible cationvacancy exchanges. The error bars depict the spread of these activation energies. The Kröger-Vink notation in the legend is similar to Fig. 8.

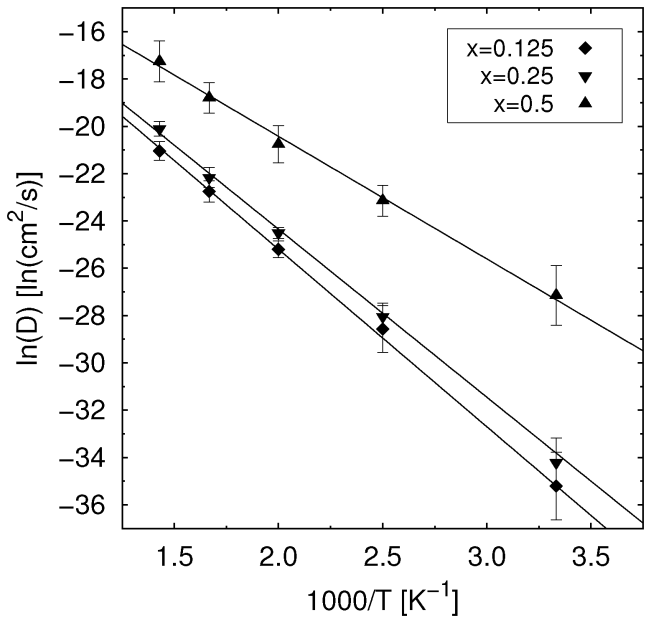

Fig. 10 Arrhenius plots of the diffusion coefficient of a $\mathrm{Li}^{1-}$ vacancy for low $(x=0.125)$, intermediate $(x=0.25)$, and high $(x=0.5)$ lithium concentrations. The error bars on the data points are the standard deviations computed based on 10 kinetic Monte Carlo cycles, each containing $10^{5}$ iterations.

more likely to exchange places with a low activation energy $\mathrm{Li}^{+}$ neighbor. This conclusion is confirmed below.

The spread in the effective activation energies, indicated by the error bars in Fig. 9, increases with the oxidation state of the cations. The origin of the spread is mainly attributed to the energy difference between initial and final configuration of the vacancy-cation exchange. For example, in the $\mathrm{Mg}^{2+}$ reaction path shown in Fig. 8, the final configuration (B) is more stable than the initial one (A). Therefore, the effective energy barrier of this transition is asymmetric going from A to B with respect to its reverse path, this results in a deviation around the average values of $0.4 \mathrm{eV}$. The increasing spread observed with the oxidation state of the cations on the other hand is explained by the differences in local charge distribution of (8a) cation neighborhoods upon a transition. Indeed, as shown in Fig. 5, an average neighborhood charge close to the + II oxidation state of the $\mathrm{Mg}^{2+}$ cations is energetically favorable. Because a cation with a higher oxidation state has a more pronounced influence on the electrostatics, a larger enthalpy difference between states A and B can be obtained. As discussed above, this increasing energy difference results in a larger spread of the effective activation energies.

The diffusion coefficient of a $\mathrm{Li}^{1-}$ vacancy is significantly higher for the $\left(\mathrm{Al}_{x} \mathrm{Mg}_{1-2 x} \mathrm{Li}_{x}\right) \mathrm{Al}_{2} \mathrm{O}_{4}$ stoichiometries that contain more $\mathrm{Li}^{+}$ions, as shown in Fig. 10 and Table 2. The difference in $D$ for low $(x=0.125)$ and intermediate $(x=0.25)$ Li concentrations is small, a clear difference is found for the high $\mathrm{Li}$

Table 2 Activation energy of diffusion $E_{\mathrm{a}}$ and pre-exponential diffusion coefficient $D_{0}$ computed for different $\left(\mathrm{Al}_{x} \mathrm{Mg}_{1-2 x} \mathrm{Li}_{x}\right) \mathrm{Al}_{2} \mathrm{O}_{4}$ stoichiometries $x$

\begin{tabular}{lll}
\hline Stoichiometries $x$ & $E_{\mathrm{a}}[\mathrm{eV}]$ & $D_{0}\left[\mathrm{~cm}^{2} \mathrm{~s}^{-1}\right]$ \\
\hline 0.125 & 0.65 & $0.4 \times 10^{-4}$ \\
0.250 & 0.61 & $0.4 \times 10^{-4}$ \\
0.500 & 0.45 & $0.4 \times 10^{-4}$
\end{tabular}


concentration $(x=0.5)$. The resulting activation energies vary across the different $\left(\mathrm{Al}_{x} \mathrm{Mg}_{1-2 x} \mathrm{Li}_{x}\right) \mathrm{Al}_{2} \mathrm{O}_{4}$ stoichiometries, with values of respectively $0.65 \mathrm{eV}, 0.61 \mathrm{eV}$ and $0.45 \mathrm{eV}$ when $x$ equals $0.125,0.25$, and 0.5 . The computed pre-exponential diffusion coefficients are similar, with a rather low value of $0.4 \times$ $10^{-4} \mathrm{~cm}^{2} \mathrm{~s}^{-1}$ due to the stable interstitial states $(16 \mathrm{c}$ Wyckoff positions), that lower the attempt frequency of a vacancy-ion exchange. The lower activation energies of diffusion for the higher lithium concentrations originate from the low effective activation energy of a $\mathrm{Li}^{1-}$ vacancy exchange. Indeed, a higher concentration of lithium results in an enhanced probability for these low energy barrier $\mathrm{Li}^{+}$exchange reactions to occur.

The results indicate that high $\mathrm{Li}^{+}$concentrations enhance the ionic conductivity of the $\mathrm{Li}^{1-}$ vacancies, thus leading to a better power output of the solid-state battery. However, Fig. 2 and 3 show that these higher concentrations lead to, respectively, a deteriorated lattice match with the $\mathrm{Li}_{x} \mathrm{Mn}_{2} \mathrm{O}_{4}$ electrode material and a higher formation enthalpy. Consequently, the $\left(\mathrm{Al}_{x} \mathrm{Mg}_{1-2 x} \mathrm{Li}_{x}\right) \mathrm{Al}_{2} \mathrm{O}_{4}$ stoichiometry with the highest $\mathrm{Li}^{+}$concentration is possibly not the best option, due to the possible enhanced ionic resistance to cross the electrode-electrolyte interfaces, and the likelihood of forming low ionic conducting $\mathrm{LiAl}_{5} \mathrm{O}_{8}$ grains. Therefore, $\left(\mathrm{Al}_{x} \mathrm{Mg}_{1-2 x} \mathrm{Li}_{x}\right) \mathrm{Al}_{2} \mathrm{O}_{4}$ stoichiometries with a lithium concentration $x$ close to 0.3 are the best compromise to be used for an all spinel solid-state battery.

At that stoichiometry, the ionic conductivity of $\left(\mathrm{Al}_{x} \mathrm{Mg}_{1-2 x} \mathrm{Li}_{x}\right)^{-}$ $\mathrm{Al}_{2} \mathrm{O}_{4}$ has been evaluated using

$$
\sigma=\frac{c F^{2} z^{2}}{R T} D_{0} \exp \left(-\frac{E_{\mathrm{a}}}{R T}\right)
$$

in which $c$ is the defect concentration, $F$ is Faraday's constant, $z$ is the defect charge, and $R$ is the universal gas constant. Assuming a defect concentration of $1 \mathrm{at} \%$, a temperature of $300 \mathrm{~K}$, an activation energy of $0.55 \mathrm{eV}$, and a pre-exponential diffusion constant of $0.4 \times 10^{-4} \mathrm{~cm}^{2} \mathrm{~s}^{-1}$, the ionic conductivity is $\approx 10^{-8} \mathrm{~S} \mathrm{~cm}^{-1}$. This relatively low conductivity arises from the combination of the low pre-exponential diffusion constant and the relatively high value of the activation energy. However, if the electrolyte can be made thin enough, as envisioned for thin-film batteries, the overall resistance can be made low enough due to the short diffusion path. For example, for a $50 \mathrm{~nm}$ thick electrolyte, this would correspond to a resistance of $\approx 400 \Omega$ $\mathrm{cm}^{-2}$. That is about a factor of 20 better than $\mathrm{Li} / \mathrm{LiI} / \mathrm{I}_{2}$ thin-film batteries in pacemakers. ${ }^{33}$ In this respect, the $\left(\mathrm{Al}_{x} \mathrm{Mg}_{1-2 x} \mathrm{Li}_{x}\right)^{-}$ $\mathrm{Al}_{2} \mathrm{O}_{4}$ stoichiometry $x=0.3$ is a possible candidate for a thin-film all-solid-state spinel battery. Indeed, the lattice constants (8.06 $⿱$ A $)$ are relatively close to those of $\mathrm{Li}_{y} \mathrm{Mn}_{2} \mathrm{O}_{4}(8.10 \pm 0.1 \AA)$, suggesting that a smooth electrode-electrolyte interface is possible.

\section{Conclusion}

First-principles studies on the $\left(\mathrm{Al}_{x} \mathrm{Mg}_{1-2 x} \mathrm{Li} \mathrm{i}_{x}\right) \mathrm{Al}_{2} \mathrm{O}_{4}$ electrolyte indicate that this spinel structured material is potentially a good candidate for a solid-state electrolyte in an all-spinel thinfilm battery stack. Such an all-spinel concept should improve the power output of the battery, thanks to the possibility to build a smooth electrode-electrolyte interface. The latter is expected to result in continuous $\mathrm{Li}^{+}$conduction paths throughout the battery. Depositing the active materials on 3D structures can further improve the energy density. The $\left(\mathrm{Al}_{x} \mathrm{Mg}_{1-2 x} \mathrm{Li}_{x}\right) \mathrm{Al}_{2} \mathrm{O}_{4}$ stoichiometry $x=0.3$ is according to us the most promising stoichiometry, since it corresponds to an ionic conductivity of $\approx 10^{-8} \mathrm{~S} \mathrm{~cm}^{-1}$. Although this value is low, it is sufficient to provide a significant conductance in a tens of nanometers thin film. Furthermore, we predicted that the $\left(\mathrm{Al}_{x} \mathrm{Mg}_{1-2 x} \mathrm{Li}_{x}\right) \mathrm{Al}_{2} \mathrm{O}_{4}$ stoichiometry with higher lithium concentration $(x=0.5)$ shows an even better conductance, but a phase segregation is likely to occur during the growth of the film. Finally, we observe that the lattice constants of the various $\left(\mathrm{Al}_{x} \mathrm{Mg}_{1-2 x} \mathrm{Li}_{x}\right) \mathrm{Al}_{2} \mathrm{O}_{4}$ materials are close enough to those of $\mathrm{Li}_{y} \mathrm{Mn}_{2} \mathrm{O}_{4}$ to obtain a possible good match between the layers.

\section{References}

1 G. Jeong, Y.-U. Kim, H. Kim, Y.-J. Kim and H.-J. Sohn, Energy Environ. Sci., 2011, 4, 1986.

2 E. Quartarone and P. Mustarelli, Chem. Soc. Rev., 2011, 40, 2525-2540.

3 J. W. Fergus, J. Power Sources, 2010, 195, 4554-4569.

4 P. Knauth, Solid State Ionics, 2009, 180, 911-916.

5 P. H. L. Notten, F. Roozeboom, R. A. H. Niessen and L. Baggetto, Adv. Mater., 2007, 19, 4564-4567.

6 L. Baggetto, R. A. H. Niessen, F. Roozeboom and P. H. L. Notten, Adv. Funct. Mater., 2008, 18, 1057-1066.

7 F. Rosciano, P. P. Pescarmona, K. Houthoofd, A. Persoons, P. Bottke and M. Wilkening, Phys. Chem. Chem. Phys., 2013, 15, 6107-6112.

8 M. M. Thackeray and J. B. Goodenough, US Pat., 4507 371, 1985.

9 J. M. Tarascon, E. Wang, F. K. Shokoohi, W. R. McKinnon and S. Colson, J. Electrochem. Soc., 1991, 138, 2859-2864.

10 M. Thackeray, Prog. Solid State Chem., 1997, 25, 1-71.

11 K. M. Colbow, J. R. Dahn and R. R. Haering, J. Power Sources, 1989, 26, 397-402.

12 Z. Yang, D. Choi, S. Kerisit, K. M. Rosso, D. Wang, J. Zhang, G. Graff and J. Liu, J. Power Sources, 2009, 192, 588-598.

13 Y. Sha, B. Zhao, R. Ran, R. Cai and Z. Shao, J. Mater. Chem. A, 2013, 1, 13233-13243.

14 R. N. Sheftal, Epitaxial Growth of Single-Crystal Films (Review), in Growth of Crystals, ed. N. N. Sheftal, Springer, US, 1976.

15 A. Patil, V. Patil, D. W. Shin, J.-W. Choi, D.-S. Paik and S.-J. Yoon, Mater. Res. Bull., 2008, 43, 1913-1942.

16 S. Hafner and F. Laves, Z. Kristallogr., 1961, 115, 331.

17 P. Giannozzi, S. Baroni, N. Bonini, M. Calandra, R. Car, C. Cavazzoni, D. Ceresoli, G. L. Chiarotti, M. Cococcioni, I. Dabo, A. Dal Corso, S. de Gironcoli, S. Fabris, G. Fratesi, R. Gebauer, U. Gerstmann, C. Gougoussis, A. Kokalj, M. Lazzeri, L. Martin-Samos, N. Marzari, F. Mauri, R. Mazzarello, S. Paolini, A. Pasquarello, L. Paulatto, 
C. Sbraccia, S. Scandolo, G. Sclauzero, A. P. Seitsonen, A. Smogunov, P. Umari and R. M. Wentzcovitch, J. Phys.: Condens. Matter, 2009, 21, 395502.

18 J. P. Perdew, M. Ernzerhof and K. Burke, J. Chem. Phys., 1996, 105, 9982.

19 D. Vanderbilt, Phys. Rev. B: Condens. Matter Mater. Phys., 1990, 41, 7892-7895.

20 A. B. Bortz, M. H. Kalos and J. L. Lebowitz, J. Comp. Physiol., 1975, 17, 10-18.

21 D. T. Gillespie, J. Comp. Physiol., 1976, 22, 403.

22 A. F. Voter, Phys. Rev. B: Condens. Matter Mater. Phys., 1986, 34, 6819.

23 A. F. Voter, F. Montalenti and T. C. Germann, Annu. Rev. Mater. Res., 2002, 32, 321-346.

24 G. Henkelman and H. Jónsson, J. Chem. Phys., 1999, 111, 7010.

25 P. Haas, F. Tran and P. Blaha, Phys. Rev. B: Condens. Matter Mater. Phys., 2009, 79, 085104.
26 H. Berg and J. O. Thomas, Solid State Ionics, 1999, 126, 227-234. 27 M. Wagemaker, D. R. Simon, E. M. Kelder, J. Schoonman, C. Ringpfeil, U. Haake, D. Lützenkirchen-Hecht, R. Frahm and F. M. Mulder, Adv. Mater., 2006, 18, 3169-3173.

28 M. Nakayama, M. Kaneko and M. Wakihara, Phys. Chem. Chem. Phys., 2012, 14, 13963-13970.

29 S. Scharner, W. Weppner and P. Schmid-Beurmann, J. Electrochem. Soc., 1999, 146, 857-861.

30 F. Rosciano, P. P. Pescarmona and A. Persoons, abstract \#495, 218th ECS Meeting, 2010.

31 S. Murphy, B. Uberuaga, J. Ball, A. Cleave, K. Sickafus, R. Smith and R. Grimes, Solid State Ionics, 2009, 180, 1-8.

32 A. Voter, Introduction to the Kinetic Monte Carlo Method, in Radiation Effects in Solids, ed. K. Sickafus and E. Kotomin, Springer, 2005.

33 W. Greatbatch, J. H. Lee, W. Mathias, M. Eldridge, J. R. Moser and A. A. Schneider, IEEE Trans. Biomed. Eng., 1971, BME-18, 317-324. 